\title{
Erratum to: Adaptive robust simultaneous stabilization of multiple $n$-degree-of-freedom robot systems
}

\author{
Haiying Zhang ${ }^{1} \cdot$ Renming Yang ${ }^{1}$
}

Published online: 7 February 2022

(c) The Author(s), under exclusive licence to South China University of Technology and Academy of Mathematics and Systems Science, Chinese Academy of Sciences 2022

\section{Erratum to: \\ Control Theory and Technology https://doi.org/10.1007/s11768-021-00076-6}

In the published article the following funders information is missing:

This work was supported by the National Natural Science Foundation of China (G61773015, G61877028, G61803230), the Key Research and Development Plan of Shandong Province (2019JZZY020712), the Natural Science Foundation of Shandong Province (ZR2019MF032), A Project of Shandong Province Higher Educational Science and Technology Program (J18KA330, J18KA348), and the Jinan Engineering Laboratory-Intelligent Control and Cloud Platform and Implementation Plan of "1251" Talent Training Project of Shandong Jiaotong University.

The original article can be found online at https://doi.org/10.1007/ s11768-021-00076-6

Haiying Zhang

2454826766@qq.com

Renming Yang

renmingyang0222@163.com

1 School of Information Science and Electrical Engineering, Shandong Jiaotong University, Jinan 250357, Shandong,

China 